\title{
Penerapan Metode Waterfall Pada Sistem Informasi Pendaftaran Pasien Rawat Jalan Berbasis Web Mobile
}

\author{
Harma Oktafia Lingga Wijaya \\ STMIK Musirawas Lubuklinggau, Jln. Jend Besar H.M. Soeharto \\ Kel. Lubuk Kupang Kec. Lubuklinggau Selatan I Kota Lubuklinggau \\ Program Studi Sistem Informasi \\ harmaoktafialingga@gmail.com
}

\begin{abstract}
When the researchers conducted studies Implementation Method Waterfall In Registration Information System Web-Based Outpatient Mobile, researchers found that the health center belongs to the municipality located in the village of Lubuk Tanjung Lubuk Linggau felt the need for development in line with increased demand for health services for the community. PHC Tanjung Lubuk Housing is in the process of registration of outpatients manuallyor still use conventional manner, includes data recording the identity of the patient, make a list of queues, search medical records of patients, as well as card making patients. When enrollment of patients when treatment would still be written in a ledger and patient data and data ever experienced disease (medical records) was recorded in the general ledger and certain records and stored in a special file. This often times lead to errors and writing the name of the same patient when treated umpteenth time and the difficulty in grouping the data requires considerable time as well as the lack of assurance of data security. If we want to find the patient data needed to be looking in the archives of books one by one to determine such data. With the support of information technology, manual processing in the clinic can be replaced using a computer. In addition to fast and easy with the information system has been made of data processing has also become more accurate. The method used in the information system of registration of outpatient-based mobile web in BPS town Lubuklinggau this, and to know the running system, using a structured approach using several tools like Uml, use case diagrams, activity, sequence diagram, class diagram, while for the system development method using a sequential linear or often called "the development cycle of the classic" or "waterfall model / waterfall". Support software used is Xampp, Adobe Dreamweaver CS3, PHP, and MySQL databases as well as the builder of program documentation and reports. With a system based on the mobile web, which is already connected to the Internet, of course, would greatly facilitate the processing of census data suseda to be stored and will be very helpful in terms of data storage census suseda, because each finished data can be collected more quickly, accurately and save time with the specified schedule.
\end{abstract}

Keywords—waterfall, patients, mobile web

\section{Pendahuluan}

Kelebihan berobat di Puskesmas adalah lokasinya yang dekat dengan pemukiman penduduk baik di desa, kampung, kota dan juga dekat dengan keramaian.Terdapat sembilan Puskesmas di Kota Lubuklinggau antara lain Puskesmas Perumnas Lubuk Tanjung, Puskesmas Sidorejo, Puskesmas Sumber Waras, Puskesmas Simpang Periuk, Puskesmas Citra Medika, Puskesmas Taba, Puskesmas Swasti Saba, Puskesmas Petanang, dan Puskesmas Megang.

Puskesmas milik pemerintah kota yang terletak di Kelurahan Lubuk Tanjung Kota Lubuk Linggau dirasakan perlunya pengembangannya seiring meningkat kebutuhan pelayanan kesehatan bagi masyarakat. Puskesmas Perumnas Lubuk Tanjung ini proses pendaftaran pasien rawat jalan masih menggunakan cara yang manual, meliputi kegiatan pencatatan data identitas pasien, membuat daftar antrian, pencarian data rekam medis pasien, maupun pembuatan kartu pasien. Saat pendaftaran pasien ketika mau berobat masih ditulis dalam buku besar dan data-data pasien maupun data penyakit yang pernah dialami (rekam medik) masih dicatat dalam buku besar maupun arsip tertentu dan disimpan dalam berkas khusus.

Cara seperti ini sering kali mengakibatkan kesalahankesalahan dan penulisan nama pasien yang sama ketika berobat kesekian kalinya dan kesulitan dalam pengelompokan data memerlukan waktu yang cukup lama serta kurang terjaminnya keamanan data. Jika kita ingin mencari data pasien yang dibutuhkan harus mencari dalam buku arsip satu per satu untuk mengetahui data tersebut. Dengan dukungan teknologi informasi yang ada, pengolahan data secara manual di puskesmas dapat diganti menggunakan komputer. Selain cepat dan mudah dengan sistem informasi yang telah dibuat pengolahan data juga menjadi lebih akurat.

Sangat tepat suatu puskesmas juga memiliki layanan sistem informasi yang lengkap dan efisien. Untuk membantu pengolahan data pasien pada puskesmas dibuat suatu sistem informasi layanan kesehatan yang berbasis Web Mobile. Sistem informasi ini akan dijalankan secara online untuk sebagian dalam Puskesmas. Dengan adanya sistem informasi ini diharapkan akan mampu mengatasi semua masalah diatas dan dapat mempermudah tugas pegawai Puskesmas Perumnas Lubuk Tanjung Kota Lubulinggau tersebut. 


\section{METODE PENELITIAN}

Adapun metode yang digunakan dalam penelitian ini yaitu menggunakan Metode penelitian deskriptif. Metode penelitian deskriptif adalah salah satu metode penelitan yang banyak digunakan pada penelitian yang bertujuan untuk menjelaskan suatu kejadian. Seperti yang dikemukakan oleh Sugiyono (2011) "penelitian desktiptif adalah sebuah penelitian yang bertujuan untuk memberikan atau menjabarkan suatu keadaan atau fenomena yang terjadi saat ini dengan menggunakan prosedur ilmiah untuk menjawab masalah secara aktual.

\section{A. Pengertian Rancangan}

Rancangan sistem dapat didefinisikan sebagai pengambaran, perencanaan, dan pembuaan sketsa atau pengauran dari beberapa elemen terpisah ke dalam satu kesatuan yang utuh dan berfungsi (Yakub, 2012:45).

\section{B. Pengertian Sistem}

Menurut Yakub (2011:1) Sistem adalah suatu jaringan kerja dari prosedur-prosedur yang saling berhubungan, terkumpul bersama-sama untuk melakukan suatu kegiatan atau untuk tujuan tertentu.

\section{Pengertian Pendaftaran}

Pendaftaran adalah pelayanan yang diberikan kepada pasien yang masuk peskesmas untuk mendapatkan pelayanan medis untuk tujuan pengamatan, diagnosis, pengobatan, rehabilitasi, dan pelayanan lainya. Pasien akan didaftar secara detil oleh petugas dengan pengisian data yang lengkap oleh pasien. Setiap kali pasien mendaftar dibagian pendaftaran untuk pengurusan administrasi pendaftaran dan pasien harus menunjukkan kartu identitas pasien apabila pernah berobat di Puskesmas tersebut, maka pertama kali yang harus dilakukan pasien harus wajub mengisi kartu formulir pendaftaran, baik itu pasien lama aau pasien baru agar nantinya diberikan nomor antrian oleh petugas pendaftaran (Berry Fether dan Diana Barsasella, 2014 : 50)

\section{Pengertian Pasien}

Dalam Nanda Amauliane Karsintaputra, Zahroh ZA, dan Endang (2015) Berdasarkan keputusan Menteri Kesehatan RI NOMOR 296/MENKES/PER/III/2008 tentang rekam medis, pasien adalah setiap orang yang melakukan konsultasi masalah kesehatannya untuk memperoleh pelayanan kesehatan yang diperlukan baik secara langsung maupun tidak langsung kepada dokter atau dokter gigi.

\section{E. Puskesmas}

Puskesmas adalah satu kesatuan organisasi kesehatan fungsional yang merupakan pusat pengembangan kesehatan masyarakat dan membina peran serta masyarakat, di samping memberikan pelayanan secara menyeluruh dan terpadu kepada masyarakat di wilayah kerjanya dalam bentuk kegiatan pokok (M.Fais Satrianegara-Siti Saleha, 2009:29).

\section{HASIL DAN PEMBAHASAN}

\section{A. Analisa Sistem}

\section{1) Analisa Sistem Yang Berjalan}

Proses pembuatan dan penyimpanan data khusunya saat melakukan pendaftaran pasien rawat jalan, pencarian datadata, dan juga pengolahan data rekam medis pada Puskesmas Perumnas Lubuk Tanjung Kota Lubuklinggau pada saat ini masih menggunakan proses dan pengolahan data yang manual, yaitu dengan menggunakan buku besar sehingga proses pengolahan data masih berjalan lambat, data-data yang tidak beraturan dan memakan waktu yang cukup lama.

\section{2) Alternatif Pemecahan Masalah}

Dalam sistem informasi ini penulis membuat desain program pendaftaran pasien rawat jalan di Puskesmas Perumnas Lubuk Tanjung Kota Lubuklinggau dengan menggunakan bahasa pemrograman PHP, HTML, CSS dan MySQL, sehingga dapat mempermudahkan penulis dalam mendesain suatu program. Dimana saat pendaftaran pasien, pencarian data-data pasien dan proses rekam medis dapat berlangsung cepat dan tidak memakan waktu yang lama. Data-data tersebut dapat langsung diakses oleh pengguna dan proses pengolahan data untuk menghasilkan informasi yang dapat berjalan secara cepat dan akurat.

\section{B. Perancangan Sistem}

1) Perancangan Dengan Menggunakan UML (Unified Modelling Language)

\section{a) Use Case Diagram}

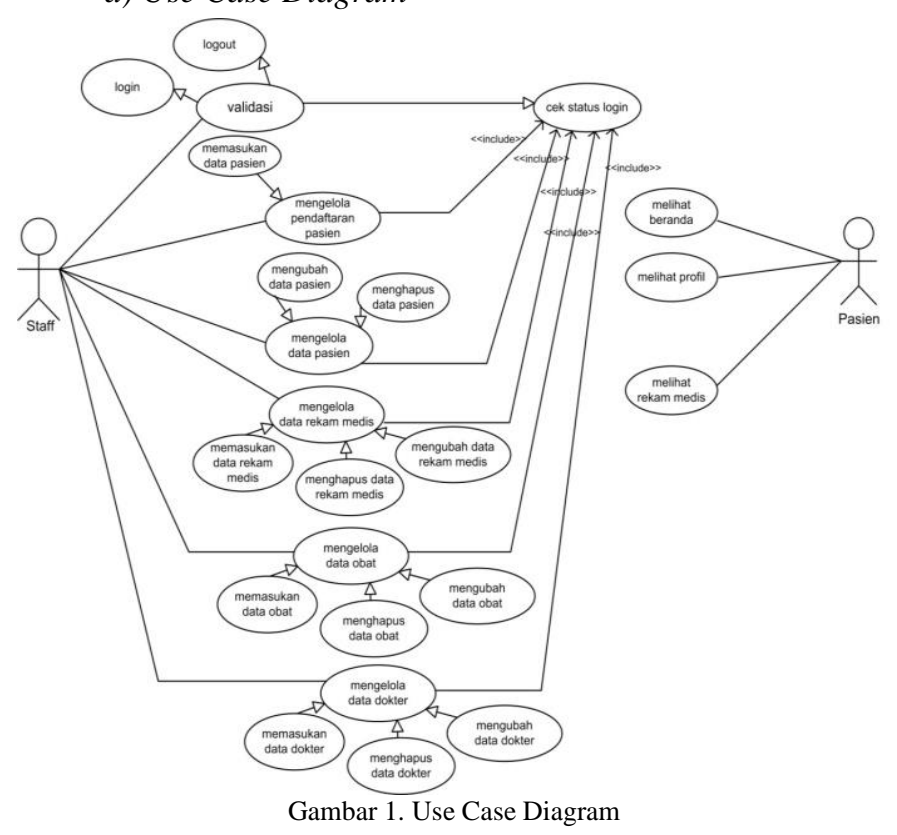

\section{2) Kebutuhan Fungsional Sistem}

Kebutuhan fungsional merupakan jenis kebutuhan yang berisi proses-proses apa saja yang mampu dilakukan oleh sistem beserta informasi-informasi yang dihasilkan oleh sistem, berikut beberapa kebutuhan fungsional dari sistem yang akan dibangun berdasarkan pengguna sistem : 
TABEL 1. KeBUtUHAN FUnGSIONAL

\begin{tabular}{|l|l|l|}
\hline NO & \multicolumn{1}{|c|}{ Deskripsi } & Prioritas \\
\hline 1 & Halaman login staff & Harus Ada \\
\hline 2 & Halaman menu utama user & Harus Ada \\
\hline 3 & Halaman menu utama home staff & Harus Ada \\
\hline 4 & $\begin{array}{l}\text { Halaman Menu Rekam Medis } \\
\text { (User) }\end{array}$ & Harus Ada \\
\hline 5 & Halaman Menu Rekam Medis Staff & Harus Ada \\
\hline 6 & Halaman Menu Pasien (User) & Harus Ada \\
\hline 7 & Halaman Menu Pasien (Staff) & Harus Ada \\
\hline 8 & $\begin{array}{l}\text { Halaman Menu Pendaftaran Pasien } \\
\text { Halaman Menu Dokter }\end{array}$ & Harus Ada \\
\hline 9 & Halaman Menu Obat & Harus Ada \\
\hline 10 & Tampilan Output Data Pasien & Harus Ada \\
\hline 11 & $\begin{array}{l}\text { Tampilan Output Data Rekam } \\
\text { Medis }\end{array}$ & Harus Ada \\
\hline 12 & Tampilan Output Data Dokter & Harus Ada \\
\hline 13 & Tampilan Output Data Obat & Harus Ada \\
\hline
\end{tabular}

\section{Pembahasan}

\section{1) Halaman Login Staff}

Halaman login ini hanya dapat dibuka oleh admin/staff yang memiliki kode staff yang telah terdaftar dalam sistem informasi ini. Tampilan menu login dapat dilihat pada gambar 2 .

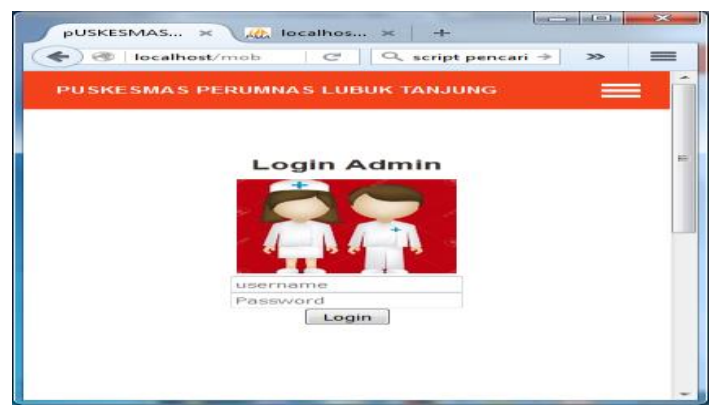

Gambar 2. Tampilan Halaman Login Staff

\section{2) Halaman Menu Utama (HOME) User}

Menu utama adalah kumpulan dari sub menu yang saling berkaitan satu sama lainnya, halaman dapat dilihat oleh user dan $\neg$ staff. Tampilan menu utama dapat dilihat pada gambar 3 .

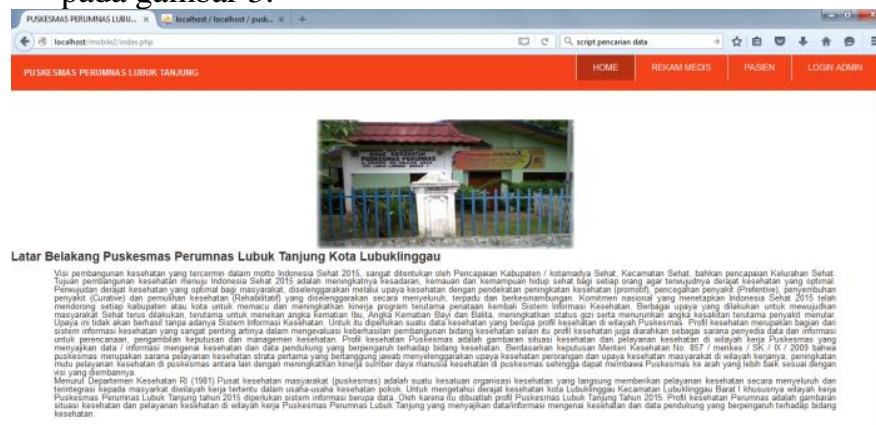

\section{3) Halaman Menu Utama (HOME) Staff}

Menu utama adalah kumpulan dari sub menu yang saling berkaitan satu sama lainnya untuk pengolahan data. Sub menunya berbeda dengan menu utama user, halaman ini hanya dapat dilihat oleh $\neg$ staff. Tampilan menu utama dapat dilihat pada gambar 4 .

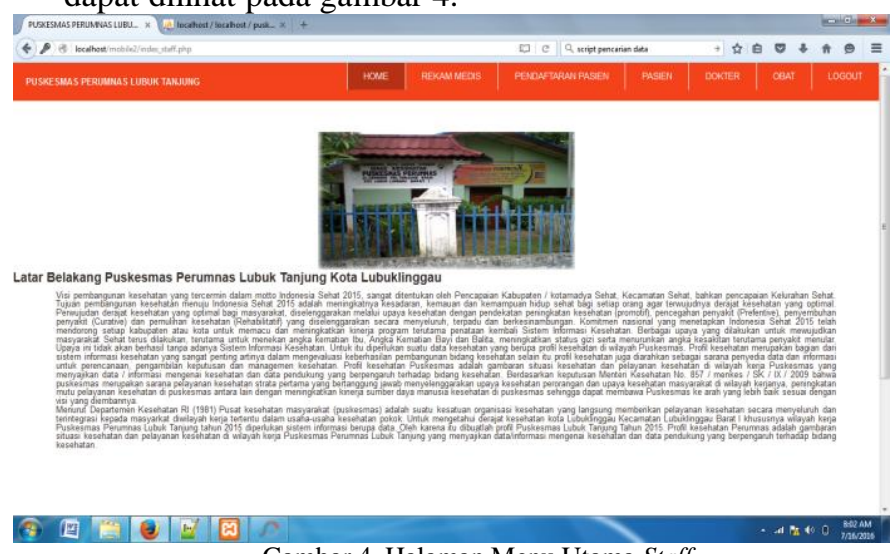

Gambar 4. Halaman Menu Utama Staff

\section{4) Halaman Menu Rekam Medis (User)}

Menu rekam medis (User) ini berguna ketika user ingin mencari data rekam medis. Tampilan menu rekam medis (user) dapat dilihat pada gambar 5.

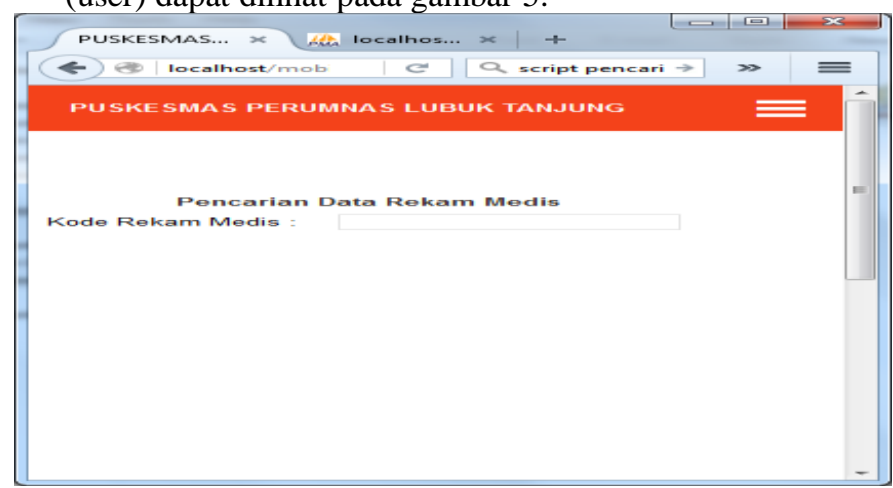

Gambar 5. Halaman Rekam Medis ( User )

\section{5) Halaman Menu Rekam Medis Staff}

Dimana menu rekam medis (Staff) ini berfungsi untuk pengolahan data rekam medis pasien dan menu rekam medis ini hanya dapat dilihat oleh staff. Tampilan menu rekam medis (Staff) dapat dilihat pada gambar 6.

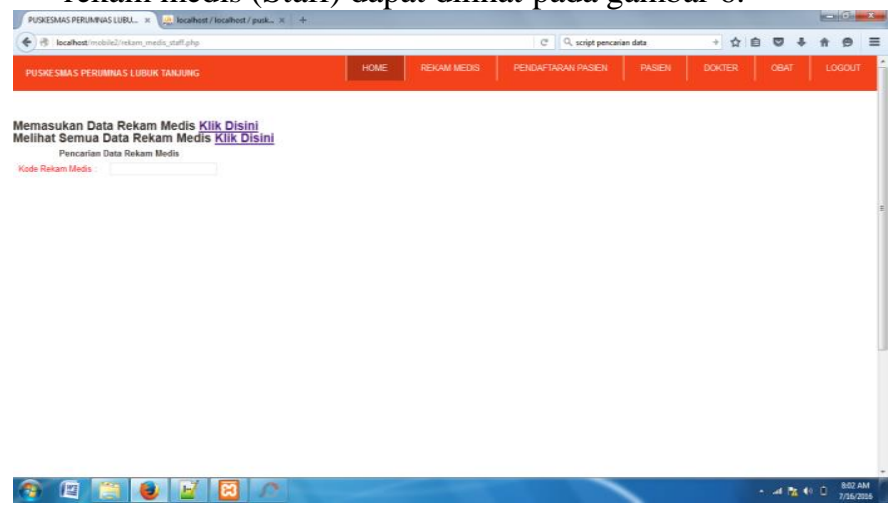

Gambar 6. Halaman Menu Rekam Medis Staff 


\section{6) Halaman Menu Utama Pasien (User)}

Menu Pasien ini untuk pengguna atau user yang ingin melihat data-data pasien. Halaman menu pasien (user) dapat dilihat pada gambar 7 .

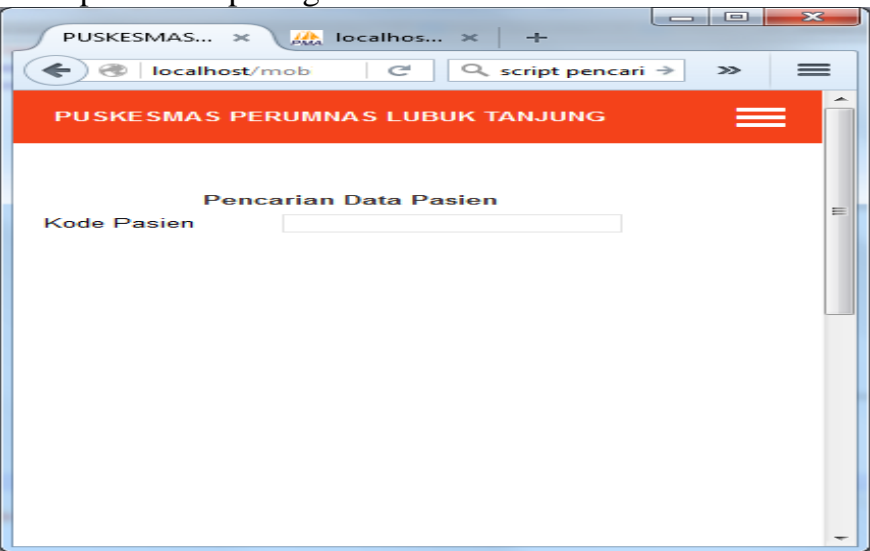

Gambar 7. Halaman Menu Pasien (User)

\section{7) Halaman menu Pasien (Staff)}

Dimana menu pasien (Staff) ini berfungsi untuk pengolahan data pasien dan menu pasien ini hanya dapat dilihat oleh staff. Tampilan menu pasien (staff) dapat dilihat pada gambar 8 .

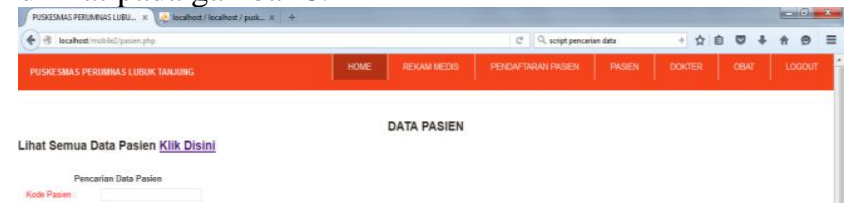

\section{9) Halaman Menu Dokter}

Halaman dokter ini untuk memasukan data dokter dan melihat data dokter. Halaman menu dokter dapat dilihat pada gambar 10 .

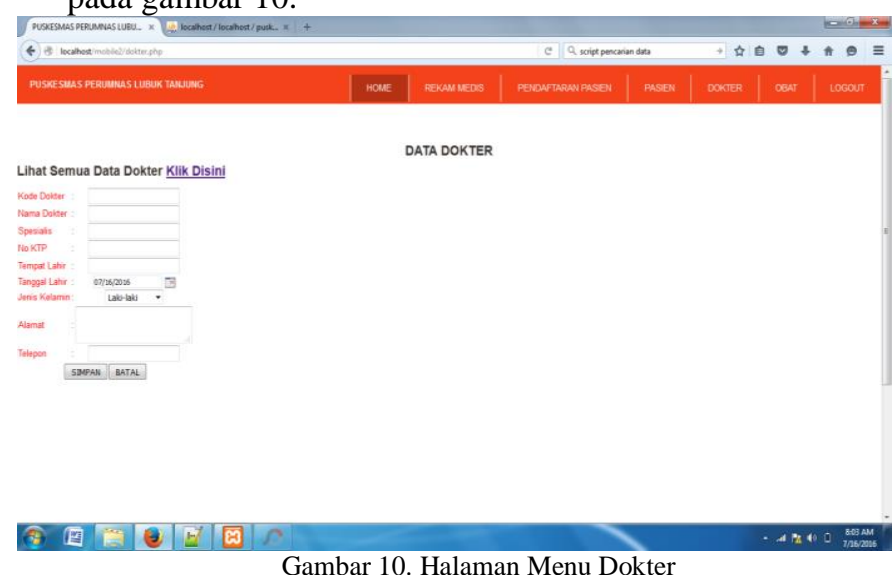

10) Halaman Menu Obat

Halaman obat ini untuk memasukan data obat dan melihat data obat. Halaman menu obat dapat dilihat pada gambar 11.

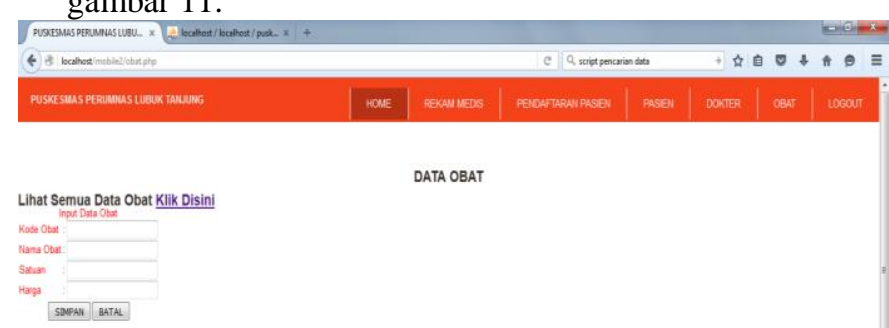

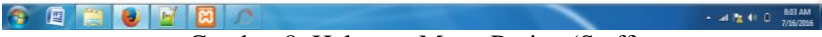

Gambar 8. Halaman Menu Pasien (Staff)

\section{8) Halaman Menu Pendaftaran Pasien}

Halaman pendaftaran pasien ini yaitu untuk memasukan data pasien agar data pasien tersebut terdaftar di dalam Puskesmas. Halaman menu pendaftaran pasien dapat dilihat pada gambar 9 .

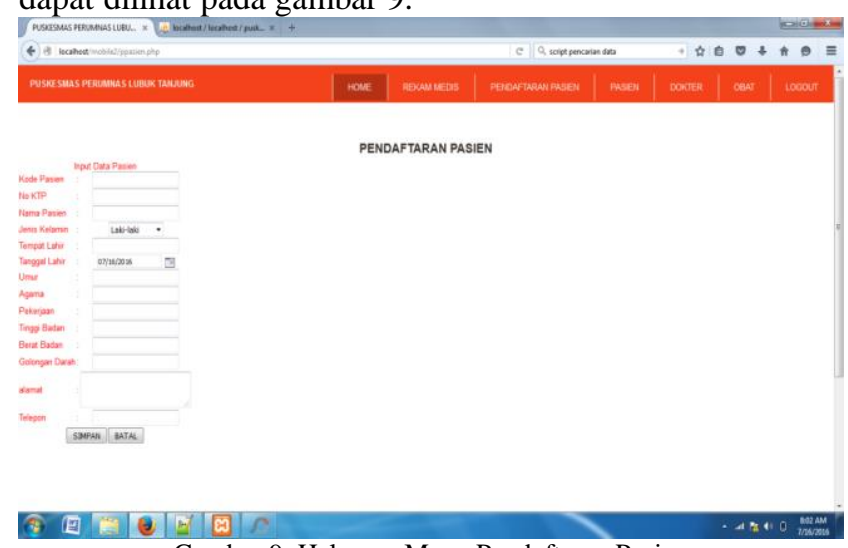

Gambar 9. Halaman Menu Pendaftaran Pasien 
12) Tampilan Output Data Rekam Medis

Halaman ini digunakan untuk menampilkan data rekam medis melalui sub program penginputan sebelumnya. Halaman ini dapat dilihat pada gambar 13.
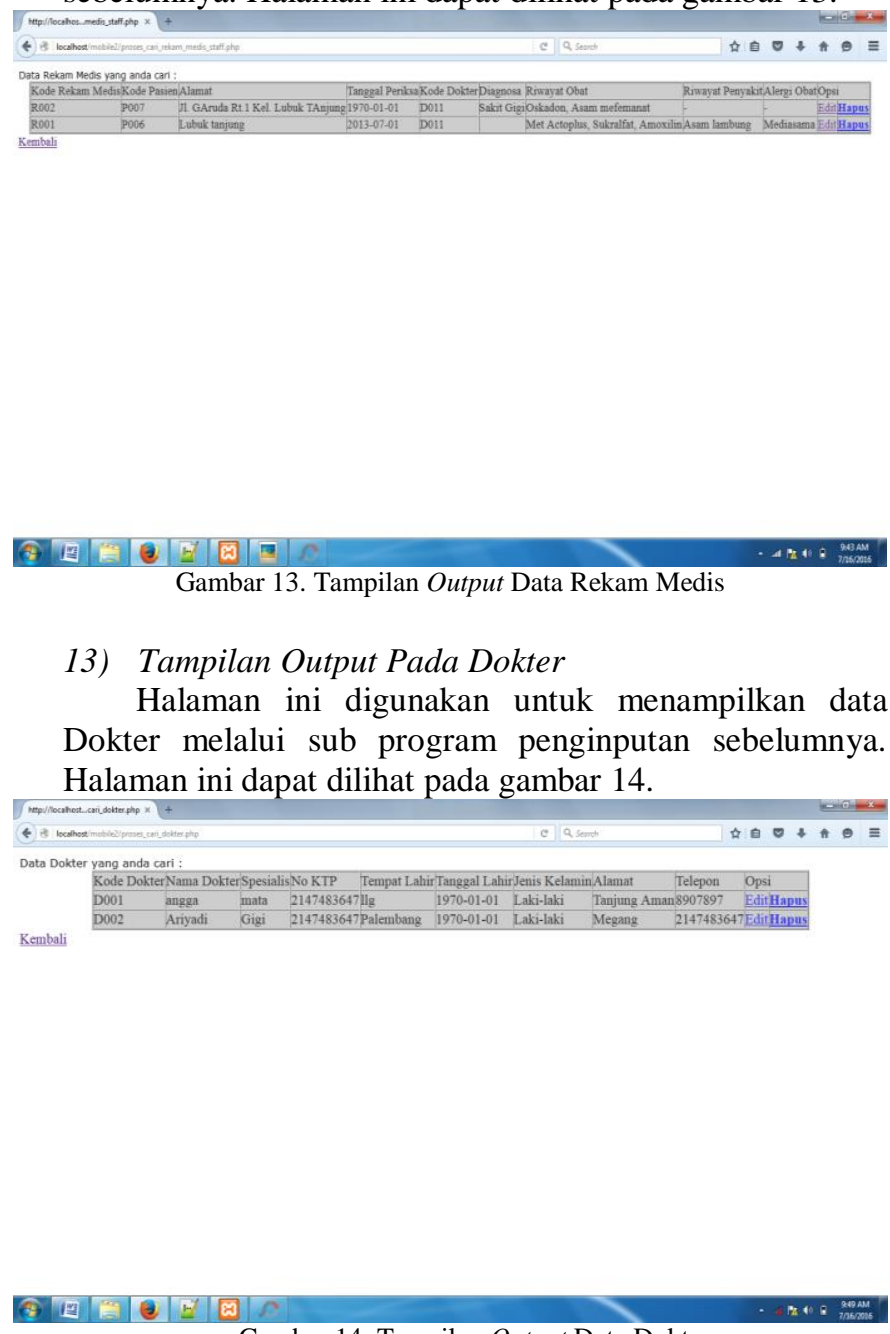

Gambar 14. Tampilan Output Data Dokter

\section{4) Tampilan Output Data Obat}

Halaman ini digunakan untuk menampilkan data obat melalui sub program penginputan sebelumnya. Halaman ini dapat dilihat pada gambar 15 .

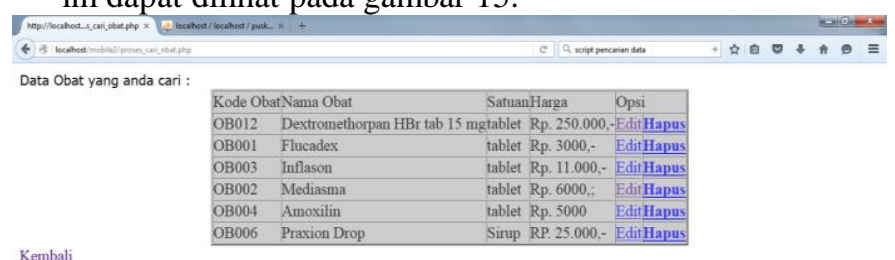

\section{PENUTUP}

\section{A. Kesimpulan}

Berdasarkan hasil pembahasan sebelumnya, maka penulis dapat menarik kesimpulan sebagai berikut :

- Sistem informasi yang dibuat ini lebih menghemat waktu staff dan pasien pada saat pendaftaran pasien.

- Sistem informasi yang dibuat ini dapat mempermudah dalam melakukan proses pengolahan data khususnya saat pendaftaran pasien.

- Sistem informasi yang dibuat ini dapat mempermudah pekerjaan staff dalam melakukan pengolahan data rekam medis pasien.

- Sistem informasi ini dapat mempercepat dan mempermudah staff dalam pencarian data-data pasien atau riwayat pasien yang lama.

- Sistem informasi yang dihasilkan dapat menghemat waktu, tenaga, dan biaya yang pada akhirnya nanti dapat menguntungkan semua pihak.

\section{B. Saran}

Beberapa kesimpulan diatas merupakan dasar untuk untuk penyusunan perbaikan proses yang sedang berjalan pada saat pendaftaran pasien rawat jalan, pencarfian data, dan pengolahan data rekam medis di Puskesmas Perumnas Lubuk Tanjung Kota Lubuklinggau. Adapun saran yang penulis berikan, yaitu :

- Sistem yang berjalan di Puskesmas Perumnas Lubuk Tanjung Kota Lubuklinggau sebaiknya terkomputerisasi secara keseluruhan tidak hanya dibagian-bagian tertentu saja.

- Kelebihan sistem informasi yang peneliti buat sebaiknya dimanfaatkan dengan seoptimal mungkin, sehingga tujuan Puskesmas Perumnas Lubuk Tanjung Kota Lubuklinggau merancang sistem komputerisasi dapat berjalan dengan efektif.

- Untuk meningkatkan keterampilan kinerja khusunya pada pendaftaran pasien rawat jalan, pencarian data dan pengolahan data rekam medis, diharapkan Puskesmas Perumnas Lubuk Tanjung Kota Lubuklinggau mengadakan pelatihan yang cukup agar sumber daya komputer yang tersedia selama ini dapat dimanfaatkan secara manual.

\section{DAFTAR PUSTAKA}

[1] Dian Permatasai dan Nurgiyatna, 2014.’Perancangan Sistem Informasi Layanan Kesehatan Puskesmas Ngempal Kabupaten Boyolali”, Jurnal. Diakses 5 Desember 2015 
[2] M.Fais, Satrianegara, dan Sitti Saleha, 2009. "Organisasi dan Manajemen Pelayanan Kesehatan serta Kebidanan”, Penerbit Salemba Medika, Jakarta

[3] Priestley, Mark, 2003."Pratical Object-Oriented Design With UML", McGraw-Hill Education, Maidenhead, Berkshire

[4] Rosa A.S, dan M. Shalahudin, 2013. "Rekayasa Perangkat Lunak Berstruktur dan Berorientasi Objek", Informatika Bandung, Bandung

[5] Sadeli, Muhammad, 2014. "Aplikasi Bisnis dengan php dan MySQL". Penerbit Maxikom, Palembang
[6] Sibero, Alexander F.K, 2011."Kitab Suci Web Programming", Mediakom, Yogyakarta

[7] Simarmata, Janer, 2006."Aplikasi Mobile Commerce Menggunakan PHP dan MySql”, Andi, Yogyakarta

[8] Supraba Angga dan Utami Ema, 2013.”Analisis dan Perancangan Sistem Informasi Pendaftaran Pasien Pada Puskesmas Pakem Yogyakarta", Jurnal. Diakses pada 16 Maret 2016

[9] Utomo, Eko, Priyo, 2013."Mobile Web Programming”, Andy Yogyakarta, Yokyakarta

[10] Yakub, 2012. "Sistem Pengantar Informasi.”, Graha Ilmu, Yogyakarta. 